\title{
Detecting flaws in composite materials - thermal model and simulation results
}

\author{
by G. Gralewicz*, J. Woźny**, G. Owczarek* and B. Więcek**
}

\section{* Central Institute for Labour Protection National Research Institute, Lodz, Poland}

** Technical University of Lodz, Poland

\section{Introduction}

Composites are presently the most developing and particularly attractive special-purpose construction materials for ballistic applications, among others. They are the basic raw materials used in the production of composite ballistic shields, such as shrapnel and bullet-proof helmets, means of transport armour, bullet-proof shields, explosion protection, additional ballistic insets for shrapnel and bullet-proof vests, etc.

The term "composite" means a non-homogeneous material structure. Composites may be composed of metal and non-metal materials used in various combinations. By selecting the right components, you can obtain a composite material that has the required properties and therefore allows to achieve benefits like lower weight, greater impact strength and better energy absorption.

The above properties are strongly impaired if a composite develops defects (in the technological process as well as subsequent use) such as ply separation, air bubbles and delamination, which are usually created as a result of impacts. The Authors propose a thermal model of a composite material with introduced defects, which allowed to conduct a series of computer simulations to locate the inclusions and decrements in the composite $[1,2,4-6,9-10]$.

\section{Thermal model}

The modelled material was a kevlar composite composed of over a dozen layers of kevlar fabric stiffened with formaldehyde resin. Because of the number of layers (more than a dozen), it was assumed in the simulations that the material is homogeneous. Defects that in reality result from random structural heterogeneity (e.g. air bubbles) were modelled as homogeneous areas with different technical parameters attributed. The aim of the simulations was to suggest methods of performing measurements.

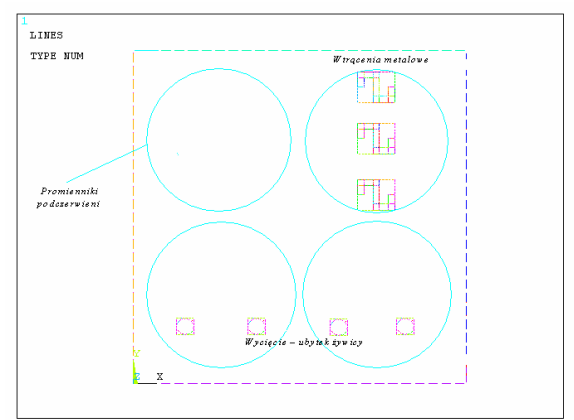

Fig. 1. Diagram of structure after limiting the area used for computer modelling

The thermal conductivity of a composite material is much lower than that of e.g. metals. This means that areas adjacent to circles with a constant heat flux will heat up only to a small extent, and the influence of the composite's side areas will be small. This allowed us to limit the modelled area, which was reduced to $1 / 4$ of the structure. This way, only a quarter of the infrared radiation source and the composite's corner were modelled (figure 2).

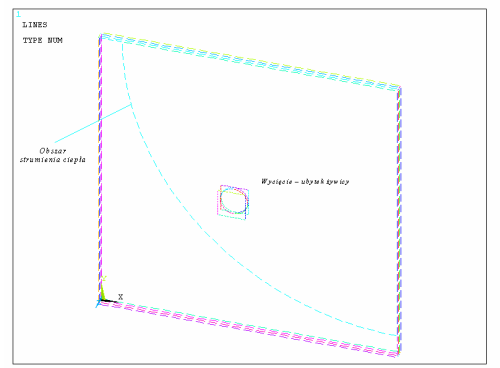

(A)

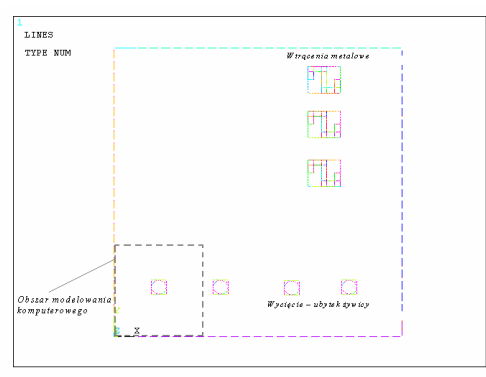

(B)

Fig. 2. Diagram of structure after limiting the area used for computer modelling (A). Diagram of composite structure with metal inclusions and defects $(B)$. View from the side of the infrared radiators 
The following structure dimensions were assumed:

- $\mathrm{x}=0.076[\mathrm{~m}]$

- $y=0.076[\mathrm{~m}]$

- $z=0.007[\mathrm{~m}]$

- $r=0.10[\mathrm{~m}]$ (radius of constant heat flux area that models the infrared radiators).

The following composite material parameters were assumed:

- Density $\rho=1152\left[\mathrm{~kg} / \mathrm{m}^{3}\right]$

- $\quad$ Specific heat $\mathrm{cW}=1400\left[\mathrm{~J} \mathrm{~kg}^{-1} \mathrm{~K}^{-1}\right]$

- Thermal conductivity $\mathrm{k}=0.3\left[\mathrm{~W} \mathrm{~m} \mathrm{~K}^{-1} \mathrm{~K}^{-1}\right]$

Average power delivered by one infrared radiator and absorbed is $\mathrm{P}=300[\mathrm{~W}]$.

Ambient temperature $\mathrm{T}_{\text {room }}=293[\mathrm{~K}]$

Heat flux $\left[\mathrm{W} / \mathrm{m}^{2}\right]$

$Q(t)=Q_{0}(1+\sin (2 \pi f t))$

Because the composite was placed in a vertical position during the measurements, identical convection coefficient values were assumed for the front and back faces:

- Front and back face: $\alpha=20\left[\mathrm{~W} \mathrm{~m}^{-2} \mathrm{~K}^{-1}\right]$

- Lateral faces: $\alpha=5\left[\mathrm{~W} \mathrm{~m}^{-2} \mathrm{~K}^{-1}\right]$

The image below shows a temperature map example:

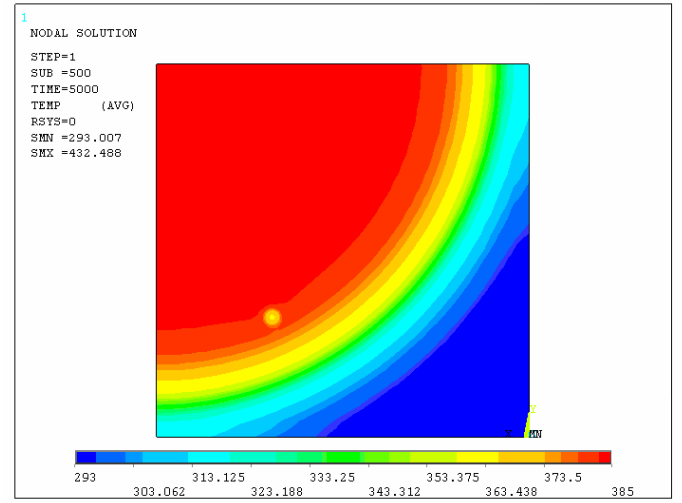

Fig. 3. Diagram Temperature map on the back side. The infrared radiator delivers an average $300 \mathrm{~W}$ to the circular area $(r=0.1 \mathrm{~m})$. Work cycle: sine wave, period $T=50 \mathrm{~s}$, total number of cycles: 5 . A cylindrical inclusion with a radius $r_{\text {inc }}=0.005 \mathrm{~m}$ and thickness $d_{i n c}=0.0005 \mathrm{~m}$ is situated at a distance of $\mathrm{l}=0.00175 \mathrm{~m}$ from the lower surface; material: air. The map shows the temperatures for a given moment in time $t=200$ s. View from the side of the infrared camera

Figure 3 shows that even at a small distance the defect no longer influences the temperature map. For this reason the modelled area was additionally limited, which allowed to increase the calculation speed significantly.

The data obtained from the simulation, which was run under ANSYS, was processed in the Matlab language. Matlab allows to visualise the results obtained as a function of time and frequency. Furthermore, it calculates the parameters that allow to determine the relative difference between the values at the location where the defect trace is expected and the neighbouring values. The script was created primarily to determine the difference between the Temperature/Amplitude/Phase (T/A/P) values at the inclusion spot and its surroundings. The point that describes the inclusion temperature $\left(p_{c}\right)$ was indicated. The T/A/P values that describe the ambience were collected at four indicated points $\left(p_{1}, p_{2}, p_{3}, p_{4}\right)$. Next, the CONTR [-] parameter was determined, which describes the difference between the T/A/P values at the inclusion and surrounding it. This parameter was defined as the absolute difference between the value in the defect's centre point $\left(p_{c}\right)$ and those surrounding it $\left(p_{i}\right.$, $i=1: 4)$ referenced to the average absolute values of $p_{c}$ and $p_{i}$.

$$
\text { CONTR }=\frac{1}{4} \sum_{\mathrm{i}=1}^{4} \frac{\left|\mathrm{p}_{\mathrm{c}}-\mathrm{p}_{\mathrm{i}}\right|}{0.5\left(\left|\mathrm{p}_{\mathrm{c}}\right|+\left|\mathrm{p}_{\mathrm{i}}\right|\right)}
$$

The absolute temperature difference between the centre point $\left(p_{c}\right)$ and the neighbouring points (pi) was then determined.

$$
\Delta \mathrm{T}=\frac{1}{4} \sum_{\mathrm{i}=1}^{4}\left|\mathrm{~T}_{\mathrm{c}}-\mathrm{T}_{\mathrm{i}}\right|
$$


The last stage was to conduct a lock-in analysis, which allowed to discover the amplitude and phase differences between the sine wave input signal and the system's response $s(t)$. The analysis used the input signal's frequency $f_{0}$ and phase $\varphi_{0}$ as parameters. The amplitude $A$ and phase $\varphi$ values of the response signal were calculated from the following formulas [3]:

$$
\begin{array}{ll}
\mathrm{A}=\frac{2}{\mathrm{~N}} \sqrt{\mathrm{SQ}^{2}+\mathrm{SP}^{2}} & \operatorname{tg}\left(\varphi-\varphi_{0}\right)=\frac{\mathrm{SQ}}{\mathrm{SP}} \\
\mathrm{SP}=\sum_{\mathrm{i}=1}^{\mathrm{N}} \mathrm{s}\left(\mathrm{t}_{\mathrm{i}}\right) \mathrm{p}\left(\mathrm{t}_{\mathrm{i}}\right) & \mathrm{SQ}=\sum_{\mathrm{i}=1}^{\mathrm{N}} \mathrm{s}\left(\mathrm{t}_{\mathrm{i}}\right) \mathrm{q}\left(\mathrm{t}_{\mathrm{i}}\right) \\
\mathrm{p}(\mathrm{t})=\sin \left(2 \pi \mathrm{f}_{0} \mathrm{t}+\varphi_{0}\right) & \mathrm{q}(\mathrm{t})=\cos \left(2 \pi \mathrm{f}_{0} \mathrm{t}+\varphi_{0}\right)
\end{array}
$$

(3)

$N$ - number of samples.

\section{Computer analysis}

The aim of the computer analysis was to determine the input signal frequency for which a defect with known parameters (location, dimensions, material parameters) could be detected. The image below shows a temperature map with the locations of the points that were used to determine the CONTR parameter.

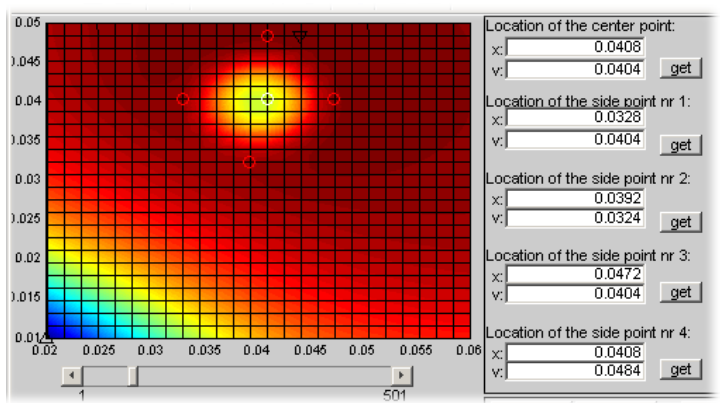

\begin{tabular}{|c|c|c|c|c|c|c|c|c|c|}
\hline $\begin{array}{l}\text { Fre } \\
\text { quency } \\
{[\mathrm{Hz}]}\end{array}$ & .001 & 0. & $.004^{0}$ & $.0045^{0}$ & $.005^{0}$ & $.0056^{0}$ & $.00(6)^{0}$ & .01 & .02 \\
\hline $\mathrm{T}[\mathrm{s}]$ & $\begin{array}{ll}000 & 5 \\
\end{array}$ & $\begin{array}{ll} & 2 \\
500 & \\
\end{array}$ & $\begin{array}{ll} & 1 \\
250 & \\
\end{array}$ & $\begin{array}{ll} & 1 \\
\end{array}$ & $\begin{array}{ll} & 1 \\
0\end{array}$ & 00 & 50 & 00 & 50 \\
\hline${ }_{1}[\mathrm{~K}] \mathrm{T}_{\max }$ & 13 & 4 & 4 & $55.5^{4}$ & 49 & $42.9^{4}$ & 31 & 93 & 67 \\
\hline${ }_{2}[\mathrm{~K}] \mathrm{T}_{\max }$ & 40 & 21 & 94 & 89 & 84 & 79 & 69.5 & 49 & 23 \\
\hline${ }_{a x}[K] \Delta T_{m}$ & 5.0 & 2.5 & 9.0 & 8.0 & 7.3 & 6.5 & 5.0 & 2.0 & .2 \\
\hline$[\mathrm{K}] \quad \Delta \mathrm{T}_{\mathrm{A}}$ & 7.8 & 5.5 & 1.9 & 1.2 & 0.6 & 0.0 & .98 & .8 & .9 \\
\hline $\mathrm{C}_{\mathrm{T}}[-$ & $.045^{0}$ & $041 \quad 0$. & $\begin{array}{ll}.033^{0} \\
\end{array}$ & $\begin{array}{ll}.031 & 0 \\
\end{array}$ & .030 & .029 & .026 & .021 & .012 \\
\hline $\mathrm{C}_{\mathrm{A}}$ & $\begin{array}{ll}.18 & 0 \\
\end{array}$ & 17 & $\begin{array}{ll} & 0 \\
.17 & \\
\end{array}$ & $\begin{array}{ll} & 0 \\
.17 & \\
\end{array}$ & .17 & $\begin{array}{ll} & 0 \\
.17 & \\
\end{array}$ & .18 & $\begin{array}{ll}.198 & 0 \\
\end{array}$ & .24 \\
\hline $\mathrm{C}_{\mathrm{P}}$ & $.0012^{0}$ & $00086^{0 .}$ & $.00062^{0}$ & $.00056{ }^{0}$ & $.00056{ }^{0}$ &.$^{0}{ }^{0}$ &.$^{0}{ }^{0}$ &.$^{0}{ }^{0}$ &.$^{0}{ }^{0}$ \\
\hline $\mathrm{C}_{\mathrm{Af}}$ & .18 & $156 \quad 0$. & .18 & $\begin{array}{ll}.20 & 0 \\
\end{array}$ & .21 & .23 & .2650 & .34 & .27 \\
\hline $\mathrm{C}_{\mathrm{Pf}}$ & $\begin{array}{ll}.026 & 0 \\
\end{array}$ & 051 & $\begin{array}{ll}.087 & 0 \\
\end{array}$ & $.0092^{0}$ & .095 & .099 & .095 & .05 & .057 \\
\hline $\mathrm{C}_{\mathrm{ALI}}$ & $\begin{array}{rr} & 0 \\
.18 & \\
\end{array}$ & $156 \quad 0$. & $\begin{array}{rr} & 0 \\
.16 & \\
\end{array}$ & $\begin{array}{rr} & 0 \\
.17 & \\
\end{array}$ & .18 & $.196 \quad 0$ & $\begin{array}{rr} & 0 \\
.22 & \end{array}$ & .28 & .23 \\
\hline $\begin{array}{ll} & \mathrm{C}_{\mathrm{PLI}} \\
{[-]} & \\
\end{array}$ & $\begin{array}{ll}.045 & 0 \\
\end{array}$ & $\begin{array}{ll} & 0 . \\
057 & \end{array}$ & $.062^{0}$ & 2 & 2 & 2 & $\begin{array}{ll}.065 & 0 \\
\end{array}$ & $\begin{array}{ll}.053 & 0 \\
\end{array}$ & .020 \\
\hline
\end{tabular}

Fig. 4. Locations of points used in subsequent analysis to determine the CONTR parameters

Table 1. This values for different heat source frequencies at a constant average power $P$ Average $=300 \mathrm{~W}$

$\mathrm{t}[\mathrm{s}]$ - heating time

$\mathrm{T}_{\max 1}[\mathrm{~K}]$ Maximum temperature on front face 
$\mathrm{T}_{\max 1}[\mathrm{~K}]$ Maximum temperature on back face

$\Delta \mathrm{T}_{\max }[\mathrm{K}]$ Maximum temperature difference in time between the centre point and the surrounding points

$\Delta \mathrm{T}_{\mathrm{A}}[\mathrm{K}]$ Average temperature difference in time between the centre point and the surrounding points

$\mathrm{C}_{\mathrm{T}}[-]$ - Average CONTR parameter for temperature

$\mathrm{C}_{\mathrm{A}}[-]$ - Average CONTR parameter for amplitude

$\mathrm{C}_{P}[-]$ - Average CONTR parameter for phase

$\mathrm{C}_{\mathrm{Af}}[-]$ - CONTR parameter for amplitude for a line corresponding to the heat source frequency

$\mathrm{C}_{\mathrm{Pf}}[-]$ - CONTR parameter for phase for a line corresponding to the heat source frequency

$\mathrm{C}_{\mathrm{ALI}}[-]$ - CONTR parameter for amplitude for LOCK-IN analysis

$\mathrm{C}_{\mathrm{PLI}}[-]$ - CONTR parameter for phase for LOCK-IN analysis

\subsection{Influence of power on analysis parameters}

As the results were so far provided for the same values of average power, it remained to test how the parameters would behave if the input power varied.

For this purpose, simulations were conducted for frequencies of $0.01 \mathrm{~Hz}$ and $0.005 \mathrm{~Hz}$. The results are displayed in tables 2 and 3.

Table 2. Parameter values for different heat source power for a selected frequency of $f=0.01 \mathrm{~Hz}$

\begin{tabular}{|c|l|l|l|l|}
\hline Power $[\mathrm{W}]$ & 150 & 300 & 450 & 600 \\
\hline \hline $\mathrm{T}_{\max 1}[\mathrm{~K}]$ & 348 & 393 & 460 & 516 \\
\hline $\mathrm{T}_{\max 2}[\mathrm{~K}]$ & 321 & 349 & 378 & 406 \\
\hline$\Delta \mathrm{T}_{\max }[\mathrm{K}]$ & 6.0 & 12.0 & 17.8 & 23.7 \\
\hline$\Delta \mathrm{T}_{\mathrm{A}}[\mathrm{K}]$ & 3.4 & 6.8 & 10.2 & 13.7 \\
\hline $\mathrm{C}_{\mathrm{T}}[-]$ & 0.011 & 0.021 & 0.029 & 0.037 \\
\hline $\mathrm{C}_{\mathrm{A}}[-]$ & 0.198 & 0.198 & 0.198 & 0.198 \\
\hline $\mathrm{C}_{\mathrm{P}}[-]$ & 0.00083 & 0.00083 & 0.00083 & 0.00083 \\
\hline $\mathrm{C}_{\mathrm{Af}}[-]$ & 0.34 & 0.34 & 0.34 & 0.34 \\
\hline $\mathrm{C}_{\mathrm{Pf}}[-]$ & 0.05 & 0.05 & 0.05 & 0.05 \\
\hline $\mathrm{C}_{\mathrm{ALI}}[-]$ & 0.23 & 0.28 & 0.30 & 0.31 \\
\hline $\mathrm{C}_{\mathrm{PLI}}[-]$ & 0.071 & 0.053 & 0.045 & 0.041 \\
\hline
\end{tabular}

Table 1. Parameter values for different heat source power for a selected frequency of $f=0.005 \mathrm{~Hz}$

\begin{tabular}{|l|l|l|}
\hline Power $[\mathrm{W}]$ & 300 & 600 \\
\hline \hline $\mathrm{T}_{\max 1}[\mathrm{~K}]$ & 449 & 606 \\
\hline $\mathrm{T}_{\max }[\mathrm{K}]$ & 384 & 475 \\
\hline$\Delta_{\max }[\mathrm{K}]$ & 17.3 & 35 \\
\hline$\Delta \mathrm{T}_{\mathrm{A}}[\mathrm{K}]$ & 10.6 & 21.3 \\
\hline $\mathrm{C}_{\mathrm{T}}[-]$ & 0.030 & 0.05 \\
\hline $\mathrm{C}_{\mathrm{A}}[-]$ & 0.17 & 0.17 \\
\hline $\mathrm{C}_{\mathrm{P}}[-]$ & 0.00056 & 0.00056 \\
\hline $\mathrm{C}_{\mathrm{Af}}[-]$ & 0.21 & 0.21 \\
\hline $\mathrm{C}_{\mathrm{Pf}}[-]$ & 0.095 & 0.095 \\
\hline $\mathrm{C}_{\mathrm{ALI}}[-]$ & 0.18 & 0.194 \\
\hline $\mathrm{C}_{\mathrm{PLI}}[-]$ & 2 & 2 \\
\hline
\end{tabular}

\section{Conclusions:}

The values of parameters $C_{A}, C_{P}, C_{A f}$ and $C_{P f}$ do not depend on the power. This is understandable if you realise that the adopted material parameters are independent of temperature, which makes the set-up a linear system. Its amplitude and phase response do not depend on the energy input.

The values $C_{A L I}$ and $C_{P L I}$ depend on the power; however, $C_{P L I}$ is constant and equal to 2 for the determined optimum frequency.

Due to the above findings, we propose to use the parameter $\mathrm{C}_{\mathrm{Pf}}$ to determine the "optimum" input frequency. Its maximum value indicates the "optimum" frequency.

\section{Thermographic test results}

The aim of the thermographic tests was to verify the input signal frequency that was determined from the computer analysis, for which the defect was detectable. The computer analysis suggested a frequency of approx. $0.005 \mathrm{~Hz}$. A sample for control testing was prepared, in which fragments of material layers were removed (from the 2nd, 4th and 6th layers from the top). The removed bits corresponded to defects (such as delamination and air bubbles) that could be created during the production process. 
A measurement system was used for the tests that allowed us to measure the real-time temperature changes of the tested body resulting from the thermal input. The system included: an infrared camera, a computer with the appropriate software (generator control and thermal image processing), and an A-D signal converter for the infrared camera (figure 5).

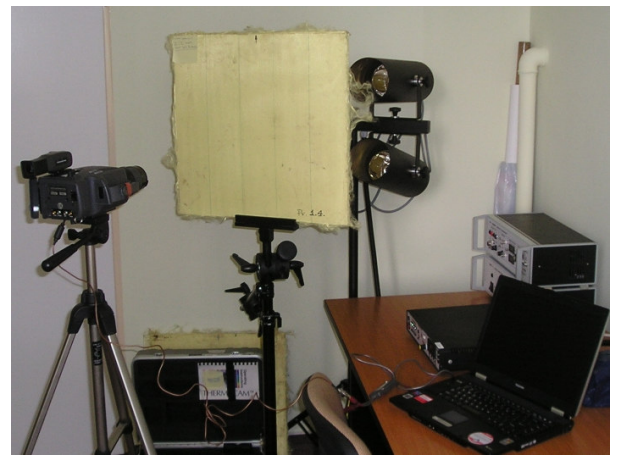

Fig. 5. Measuring station for non-destructive testing using active thermographic technique

Measuring system parameters:

- $\quad$ Stimulation types: impulsive, periodical.

- Generated wave length range: $500-1700 \mathrm{~nm}$

- Generated beam power range: $90-375 \mathrm{~W}$.

- Infrared image analysis spectral range: $3-5 \mu \mathrm{m}$

- Infrared image analysis sensitivity: $0.1^{\circ} \mathrm{C}$

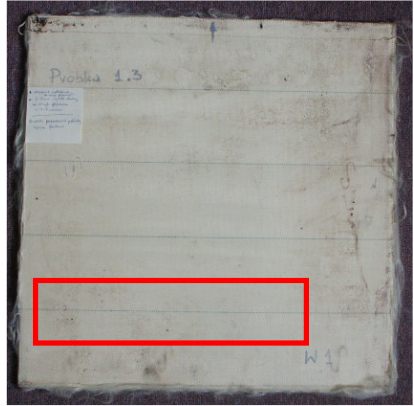

(A)

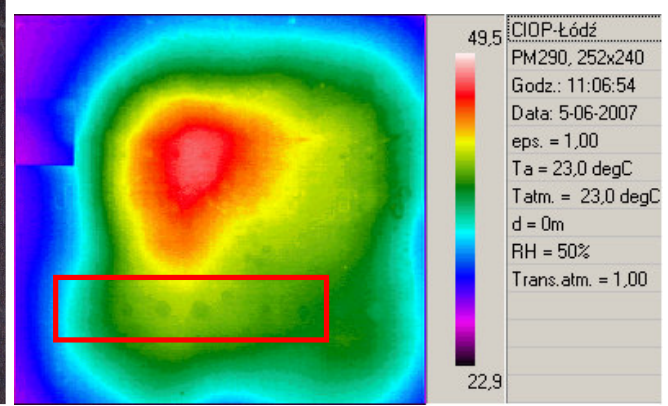

(B)

Fig. 6. Periodical stimulation $0.005 \mathrm{~Hz}$ (infrared radiators $4 \times 375 \mathrm{~W}$.

(A)- photograph of tested material, (B)- thermogram with marked cutout areas - resin deficiency

\section{Conclusions:}

Cylindrical cutouts of material fragments from the $2^{\text {nd }}$ layer from the top can be located (see figure 6).

The input frequency $(f \approx 0.005 \mathrm{~Hz})$ indicated by the computer analysis was confirmed as the frequency that enables locating the defects for a given case.

The results of the thermographic tests confirm that it is possible to locate sub-surface defects that are characterised by different thermal properties from those of the base material (the composite).

\section{Discussion}

\subsection{Temperature difference}

Because the simulation time was set to a constant number of power signal cycles (five cycles), the actual time varied depending on the input frequency. This means that a steady state was not achieved in every case. For higher frequencies (above approx. $0.005 \mathrm{~Hz}$ ) the plate was being constantly heated up without achieving a steady state. The maximum temperature difference $\Delta T_{\max }$ diminished with higher frequencies. This was because the higher the frequency was, and therefore the shorter the heating time, the less energy was delivered to the plate causing smaller temperature differences (expressed in absolute units). The above observation led to the conclusion that inputting a constant signal of the same mean power long enough to attain a steady state value would be best. It must be emphasised that this situation would not allow detecting defects with the same thermal conductivity but merely different heat capacity. Only dynamic states enable detecting the difference resulting from varying thermal capacities.

\subsection{FFT analysis}

An FFT analysis allows detecting phase shifts and the relations between the individual harmonic components for different frequencies [2,5,6,9]. Because the input signal was a sine wave, the most important 
observation was to note the amplitude and phase at a frequency corresponding to the input signal frequency. Because the input signal consists of five periods.

The phase and amplitude difference was observed between the inclusion centre point and the surrounding points. The predefined CONTR parameter was used to measure the differences. It is calculated for the amplitude and the phase. The parameter determined for the line that corresponds to the input source frequency was marked as $C_{A f}$ and $C_{P f}$ (see table 1). Because we are interested in finding out if any characteristic frequency exists, we are looking for a parameter that would adopt the minimum or maximum value at the given frequency. This parameter is $C_{P f}$, which measures the phase shift differences for each point. The simulations that were carried out imply that this value is the largest for a frequency of $0.0056 \mathrm{~Hz}$. The maximum value means that for this frequency the phase shift between the inclusion centre point and the surrounding points was the largest, which allows detecting the inclusion more precisely.

\subsection{Lock-in analysis}

The lock-in analysis is similar to the conducted FFT analysis except that it shows what the phase shift and response amplitude look like relative to the input signal [12]. In other words, the response signal is analysed only in the frequency corresponding to the power input signal.

The lock-in (and FFT) analyses allow to create an amplitude and phase shift map for the entire surface watched. Similar to the FFT, here too the CONTR coefficient was determined for the phase and amplitude, respectively $C_{P L I}$ and $C_{A L I}$. The value of $C_{P L I}$ (see table 1) also attained its maximum for a frequency of $0.0056 \mathrm{~Hz}$. A value of 2 means that the phase is reversed. The value of $C_{P L I}=2$ was also achieved at other frequencies, but then the area above the reverse-phase inclusion is smaller.

\subsection{Thermographic tests}

The thermographic tests conducted allowed us to verify the input signal frequency determined during the computer analysis for which the defects were detectable. The computer analysis indicated a frequency of 0.0056 $\mathrm{Hz}$; tests conducted at a frequency of $0.005 \mathrm{~Hz}$ enabled indicating defects such as missing bits of material layers (cylindrical cutouts). The removed fragments corresponded to defects (such as delamination and air bubbles) that are created during the production process.

\section{Summary:}

An analysis of the thermal response signal in the frequency domain and a lock-in analysis was performed.

The suggested CONTR parameter allows to determine the differences between the Temperature/Amplitude/Phase value determined for the inclusion centre point and its surroundings.

Observation of the $C_{p f}$ parameter allows to find the optimum frequency for detecting a giver inclusion.

The results of thermographic testing confirmed the frequency indicated by computer modelling as the frequency that enables locating defects for a given case.

\section{REFERENCES}

[1] A. Dillenz, D. Wu, K. Breitrück, and G. Busse, 2000, "Lock-in thermography for depth resolved defect characterization".

[2] F. Galmiche and X. Maldague, 2000, "Depth defect retrieval using the wavelet pulse phase thermography", Quantitative Infrared Thermography 5.

[3] A. Nowakowski „Postępy termografii - aplikacje medyczne” Wydział Elektroniki, Telekomunikacji i Informatyki Katedra Elektroniki Medycznej i Ekologicznej Gdańsk - 2001r.

[4] Maldague X. P. 2001, "Theory and Practice of Infrared Technology for Nondestructive Testing", John Wiley \& Sons, N. Y.

[5] G. Owczarek, G. Gralewicz „Zastosowanie promieniowania podczerwonego do lokalizacji defektów w strukturach materiałów" - monografia, CIOP-PIB, 2003, Warszawa.

[6] B. Więcek, T. Wajman, G. Gralewicz, S. Zwolenik; "Theory and measurements of single and multilayer structures using lock-in and pulse thermography"; Thermosense XXV Conference, 21-25 April 2003, Orlando.

[7] G. Busse, T. Zweschper, G. Riegert, A. Dillenz, Advanced dynamic thermography for industry-related applications; Proc. of VI TTP 2004, Ustron-Jaszowiec, 61-72, 2004.

[8] G. Gralewicz, B. Wiecek, G. Owczarek; „Zastosowanie termografii w badaniach nieniszczących”, Zeszyty Elektroniki, Politechnika Łódzka, 01.2005, s. 31-61.

[9] G. Gralewicz, G. Owczarek, B. Więcek; „Investigations of Single and Multilayer Structures Using Lock-In Thermography - Possible Applications", International Journal of Occupational Safety and Ergonomics (JOSE) 2005, Vol. 11, No. 2, 211-215.

[10] G. Gralewicz, G. Owczarek, B. Więcek; "Analytical-numerical model for the detection of structural defects by lock-in termography", Problemy Eksploatacji, 65-79, 2/2006 (61).

[11] R. Olbrycht, B. Więcek, G. Gralewicz, T. Świątczak, G. Owczarek „Comparison of Fourier and wavelet analyses for defect detection in lock-in and pulse phase thermography”, QIRT Journal. Volume $4 \mathrm{~N}^{\circ} 2 / 2007$, pages 219 to 232 . 